\title{
The Effect of Using Authentic Task on Teaching Adjectives
}

\author{
Shadi Rastegaran \\ Islamic Azad University of Garmsar, Iran \\ E-mail: shadirastgaran@yahoo.com
}

\author{
Doi:10.7575/aiac.alls.v.7n.2p.18 \\ URL: http://dx.doi.org/10.7575/aiac.alls.v.7n.2p.18
}

Received: 03/11/2015

Accepted: 02/01/2016

\begin{abstract}
In this study the researcher tried to investigate whether tasks have any effect on adjective learning or not. To achieve this purpose, the following research question was set forth by the researcher: "Does using authentic task have significant effect on adjective learning?" A proficiency test was administered to minimize the individual difference among learners and to make certain the homogeneity of them. Then, before starting the treatment, a vocabulary test was given to the learners to see if the knowledge of vocabulary items already exists among participants or not. After the test, the known words even by one learner were omitted from the whole study. Subsequently, each group received an especial kind of treatment for 12 sessions. At the end, a multiple choice vocabulary post-test similar to the pre-test was administered. _To analyze the findings of the study, SPSS (Statistical Package for social science) was utilized and the obtained results indicated that using authentic tasks contributed to the enhancement of adjective learning.
\end{abstract}

Keywords: Authentic task, task, activity, adjective, words

\section{Introduction}

Language learning is believed to depend on immersing the students not merely in comprehensible input but in tasks that require them to negotiate meaning and engage in naturalistic and meaningful communication. In recent years vocabulary has been considered to pay a more central role in second language learning than was traditionally assumed

There are different methods in vocabulary teaching that can be mainly classified into two methods; traditional and modern.

Traditional method refers to a method that provides the learners a long list of words and asks them to memorize those words. In this method there is no motivation or fun for teachers and learners.

The modern method refers to a method that provides the learners activities and authentic tasks which seem to offer the best answer to vocabulary (adjective) teaching as it relies on learners' experiences and reality to facilitate learning. This modern "Task-Based" method provides more opportunities for communicative interaction and cooperative relationships for learners. It would be also a motivating method for learners to be able to use various words for various purposes as native speakers do.

Considering the point mentioned, the emphasis is on using authentic materials and tasks. Researchers believe that the development of the communicative movement is a need to develop learners' skills for the real situation and it has led teachers to make an attempt to stimulate this situation in the classroom by using authentic tasks.

In this study, the aforementioned methods would be compared in study methodology section, then the results would be reflected in results and discussion section.

\section{The review of the related literature}

In this section some of the important studies done in the realm of vocabulary, task, task-based method and authenticity are briefly presented.

Vocabulary can be defined as a 'dictionary' or a set of words. According to Richards and Plat and Plat, vocabulary is a set of lexemes, including single words, compound words and idioms. (Richards, Platt, \& Platt, 1992). Rivers believes that it is impossible to learn a language without learning its vocabulary (Rivers,1981). Blackowicz and Fisher claimed that developing a strong vocabulary not only promotes reading comprehension but also enables learners to actively participate in their society. (Blachowicz, \& Fisher, (2004). Nowadays it is widely accepted that vocabulary teaching should be part of the syllabus, and taught in a well-planned and regular basis. Some authors, led by Lewis, argue that vocabulary should be the centre of language teaching, because "language consists of grammaticalised lexis, not lexicalized grammar". (Moras, 2001).

According to Thornbury "without grammar very little can be conveyed, without vocabulary nothing can be conveyed (Thornbury, 2004). So most of the learners know the importance of vocabulary acquisition. 
We are not sure the appropriate time of exposure to learn a word, but McCarthy and O'Dell described the number of exposures before really knowing a word that learners need five to seven exposures to a word or phrase before they can really know it (McCarty, \& O’Dell (1994).

From guessing at the first encounter, to possible dictionary use and note taking, to rehearsal, encoding, and contextual activation, vocabulary learning in real life situations is a dynamic process involving meta cognitive choices and cognitive implementation of a whole spectrum of strategies. Whether and how a learner evaluates the task requirement and whether and how a cognitive strategy is deployed are often dependent more on the learner than on the task. This learner-oriented process view of vocabulary acquisition that looks at naturally occurring vocabulary learning strategies as they relate to individual differences as well as the vocabulary learning task is beginning to form a new trend.

Interestingly, a more recent study done by Kojic-Sabo\& Lightbown, suggested that "time and learner independence were the two measures most closely related to success in vocabulary learning and higher overall English proficiency". (Kojic-Sabo, \& lightbown, 1999).

Moras explanation for native speakers' fluency is that vocabulary is not stored only as individual words, but also as parts of phrases and larger chunks, which can be retrieved from memory as a whole, reducing processing difficulties. On the other hand, learners who only learn individual words will need a lot more time and effort to express themselves. (Moras, 2001).

In this part, we would discuss about authentic tasks. In general, an authentic task is one which is purposeful and engaging, models how people solve real problems in work and/or communities, puts knowledge to work, potentially demonstrates what learners know and can do, supports multiple representations and solution strategies, offers opportunities for meaningful learning. Tasks, according to Nunan, are activities which can stand alone as units and they require comprehending, producing, manipulating, or interacting in authentic language while attention is primarily paid to meaning rather than form. (Nunan, 1989). He confirms that task is different from exercise, "Task has a nonlinguistic outcome while an exercise has a linguistic outcome".

According to Garins and Redman, learning is the most effective if learners are actively engaged in a task which is the final motivating and challenging. Besides, it is essential for learners to have opportunities to use and understand the relevance new language to their personal involvement (Grains \& Redman,1995). Newton has proved the qualification of this approach. Leaving learners with mixed abilities in each group, letting them work together and solve the task make them gain their abilities to identify unfamiliar words from the tasks. As a result, it promotes oral fluency and pursues actively communicative goals.

In these cooperative options, however, the role of teachers is vital. They may need to work with groups to show learners how to draw on context clues. By lynch's opinion, the teacher may also need to assist in negotiation, monitor performance, observe difficulties and look for positive features of performance to raise in post-task discussion. (Lynch, 1997). Newton says the teacher needs to ensure that learners are given opportunities to meet and explore new vocabulary without direct teacher assistance, and to use this vocabulary to meet meaningful tasks goals.

Blackburn confirms that this method transfers teacher from playing the role of the selector, presenter, and evaluator to playing a role of brainstormer, manager, and leader. (Blackburn, 2003). The teacher's role, as stated by Mueller, is no longer the traditional information giver. (Mueller, 2003).

Richards and Rodgers define task-based language teaching to an approach based on the use of tasks as the core unit of planning and instruction in language teaching. (Richards \& Rodgers, 2001).

Task-based approach is based on several principles:

1. Activities that involve real communication are essential for language learning.

2. Activities in which language is used for doing meaningful tasks promote learning.

3. Meaningful language supports the learning process.

Nunan stated that task-based language teaching has the following characteristics:

1. Emphasis on interaction in the target language

2. Using authentic texts

3. Focusing not only on language but also on the learning process itself

4. Enhancing learners' own personal experiences

5. Linking classroom language with language outside the classroom. (Nunan, 1991).

Skehan claims that in the task-based approach the emphasis is on the learner. So it requires a skillful and responsive teacher who is able to cope with groups of learners. (Skehan, 2002). Richards and Rodgers believe a central role of the teacher is selecting, adapting, and sometime creating the tasks themselves based on the learners' needs, interests, and language skill level. (Richards \& Rodgers, 2001).

Carlson states that the classroom is learner-centered. The learners bring with them into class their knowledge, skills, attitudes, and beliefs. Learners are encouraged to ask questions, engage in social discourse, and find their own answers. They are active learners because they do more than passively sit and listen to their teacher talk. They must be active participants in the learning process, by writing, discussing, analyzing evaluating the information (Carlson, 2004). 


\section{The structure of the study}

\subsection{Statement of the problem}

Teachers, students, material developers and researchers all agree that learning adjectives under the title of vocabulary is the most essential part of mastering a language.

Language learners also need to be able to use various words for various purposes as native speakers do. In fact, due to their lack of familiarity with newspapers and magazines in the language, they may spend even more time than a native speaker scanning and skimming prior to make choices.

Nowadays teachers mainly try to provide learners real life opportunities for expanding their vocabulary knowledge. To do so they provide tasks and activities for learners to make them able to communicate language being learnt.

Considering the point mentioned, the emphasis is on using authentic materials and tasks. Researchers believe that the development of the communicative movement is a need to develop learners' skills for the real situation and it has led teachers to make an attempt to stimulate this situation in the classroom by using authentic tasks.

\subsection{Study questions \& hypothesis}

The question which will be investigated in the present study is:

"Does using authentic task have any significant effect on adjective learning among Iranian intermediate EFL learners?"

In order to find the crucial answer to the above question, the following null hypothesis was developed:

HO. Using authentic tasks does not have any significant effect on adjective learning at an intermediate level.

\section{Study Methodology}

First, a group of $90 \mathrm{EFL}$ learners were chosen. The researcher needed a standard criterion to assess the homogeneity of the participants. So the Nelson English Language Test, comprising of 50 items was administered. Those learners whose scores were in the range of one SD below to one SD above the mean score were selected and divided in two groups. The subjects participating in this study were 62 EFL learners.

1. Experimental Group $=$ comprised of 32 learners that read texts about zodiac signs.

2. Control Group =comprised of 30 learners that read dictionary extract of new words other groups received.

Second, to ensure that the knowledge of the adjectives aimed at this study did not exist among participants a vocabulary pre-test was administered before giving the treatment.

The pre-test was comprised of $\mathbf{7 7}$ multiple choice questions checking the learners' knowledge of the vocabulary. After the test, the known words were omitted from the treatment and post-test as well.

Third, 12 texts about 12 zodiac signs and also dictionary extracts were used in this study.

Fourth, the participants' acquisition of adjectives was measured through a multiple choice post-test which was a vocabulary test similar to the pre-test.

Learning should not be confused with unattended learning. During the task, the learners may attend to the words by using them in sentences or by looking them up in a dictionary.

They found that looking up new words in a dictionary during a task is effective for learning those words. So the learners in this study were asked to look the unknown words up in their dictionaries.

At last, a post test comprising of 42 multiple choice test, was administered to measure the participants' acquisition of adjectives.

Texts and dictionary extracts were given to experimental and control groups respectively. Each session, group E (i.e. the group that read texts as its treatment) received the adjectives in printed formats. There are 12 months and consequently 12 zodiac signs. Everybody has his or her own sign according to their birth month. It is believed that each sign affects the character and life of people born under it. Every session, learners received a short text about one of the signs, they were asked to look up the unknown words up in their dictionaries.

At the end of each session they were asked to write a short description using the learned adjectives about one of their classmates or family member born under the same sign.

Participants in group C (i.e. control group) received the dictionary extract of the adjectives that experimental group received.

The present study was designed to determine the effects of using authentic task on adjective learning.

Therefore, the independent variable was the authentic task and the dependant variable was adjective learning.

The researcher used "pre-test post-test intact groups" design in her EFL classes to accomplish the mentioned goal. To see the difference among performances in the two groups, T-test was conducted. Computer based statistical program such as SPSS (Statistical Package for social science) was assisted in this regard.

\section{Results \& Discussion}

The results and data obtained from the comparison between two methods and groups are displayed in two sections; vocabulary pre-test and vocabulary post-test results: 


\subsection{The results of vocabulary pre-test}

To be certain that none of the vocabularies targeted at this study was already in participants' background knowledge, a multiple choice pretest comprising of 77 vocabulary items was conducted. Tables 1 and 2 respectively show the descriptive statistics results of scores of the participants in control and experimental groups on the pre-test.

Table 1. Descriptive Statistics of the control group in pre-test

\begin{tabular}{ccccccccc}
\hline & N & Range & Minimum & Maximum & Sum & Mean & Std. Deviation & Variance \\
\hline Scores & 30 & 30 & 12 & 42 & 778 & 25.93 & 8.710 & 75.857 \\
\hline Valid N & 30 & & & & & & &
\end{tabular}

Table 2. Descriptive Statistics of the experimental group in pre-test

\begin{tabular}{ccccccccc}
\hline & N & Range & Minimum & Maximum & Sum & Mean & Std. Deviation & Variance \\
\hline Scores & 32 & 33 & 11 & 44 & 787 & 24.59 & 8.175 & 66.830 \\
\hline Valid N & 32 & & & & & & & \\
\hline
\end{tabular}

Table 3. Independent Samples Test (to compare the mean of two groups before treatment)

Levene's Test for
Equality of Variances

\begin{tabular}{|c|c|c|c|c|c|c|c|c|c|c|}
\hline & & \multirow[t]{2}{*}{$\mathrm{F}$} & \multirow[t]{2}{*}{ Sig. } & \multirow[t]{2}{*}{$\mathrm{T}$} & \multirow[t]{2}{*}{ Df } & \multirow[t]{2}{*}{$\begin{array}{l}\text { Sig. (2- } \\
\text { tailed) }\end{array}$} & \multirow[t]{2}{*}{$\begin{array}{c}\text { Mean } \\
\text { Difference }\end{array}$} & \multirow[t]{2}{*}{$\begin{array}{l}\text { Std. Error } \\
\text { Difference }\end{array}$} & \multicolumn{2}{|c|}{$\begin{array}{l}95 \% \text { Confidence } \\
\text { Interval of the } \\
\text { Difference }\end{array}$} \\
\hline & & & & & & & & & Lower & Upper \\
\hline \multirow[t]{2}{*}{ core } & $\begin{array}{l}\text { Equal variances } \\
\text { assumed }\end{array}$ & .388 & .536 & .625 & 60 & .535 & 1.340 & 2.144 & -2.950 & 5.629 \\
\hline & $\begin{array}{l}\text { Equal variances } \\
\text { not assumed }\end{array}$ & & & .623 & 59.022 & .535 & 1.340 & 2.149 & -2.960 & 5.639 \\
\hline
\end{tabular}

To prove the homogeneity of the participants in control and experimental groups before the treatment, an independent T-test was run that its' results are shown in table 3.Table 3 denotes that P-value which is .53 is more than .05. Furthermore the t-value observed, which is .62 is less that the t-value critical at the 0.05 level of significance (1.67)

Therefore, we can safely claim that the pre-test mean score of the control group is not significantly different from the pre-test mean score of the experimental group.

The similarity between Pre-test mean score in Control Group and Pre-test mean score in Experimental Group is depicted in Figure 1.

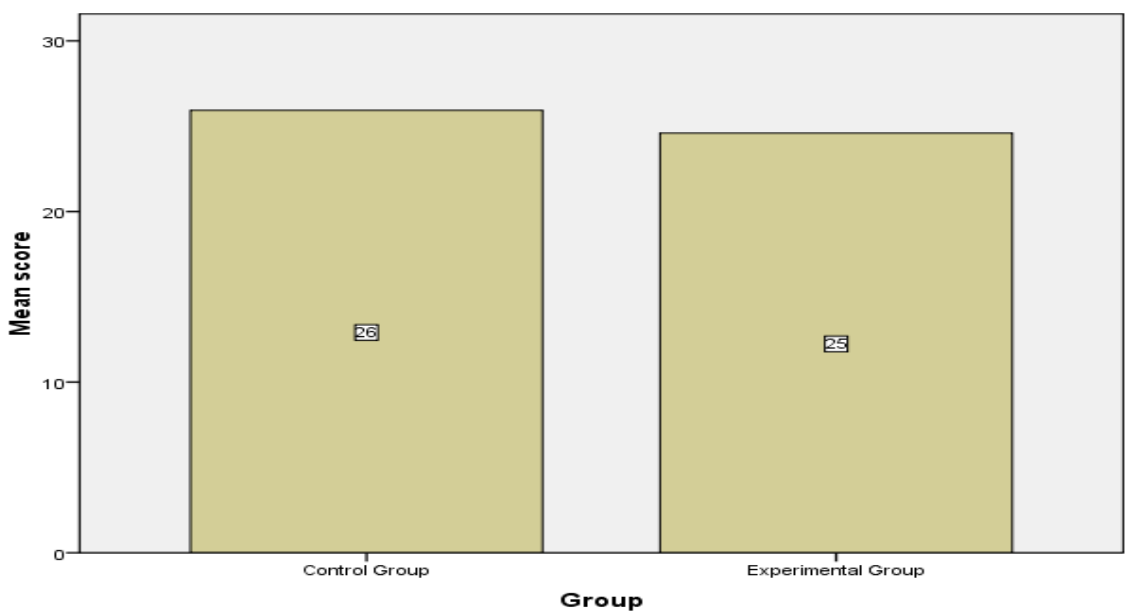

Figure 1. The comparison of two groups before treatment 
After administrating the test, the known items even by one subject were omitted from the treatment and from the vocabulary posttest as well. The result showed that only 42 words were unknown to the participants.

\subsection{The results of vocabulary post-test}

Totally two groups, an experimental and a control group, were involved in investigating the effect of authentic tasks on adjective learning. During 12 sessions, group E read some texts about zodiac signs, while group C read dictionary extract of new words that were received by the other group.

Finally, participants' acquisition of new vocabulary was measured through a post-test which was a multiple choice vocabulary test similar to the pretest. The post-test was comprised of 42 vocabulary items that were completely unknown to the learners.

Table 4 represents the scores and their frequency of the participants in control group after treatment.

Table 4. Descriptive Statistics of Control Group in Post-test

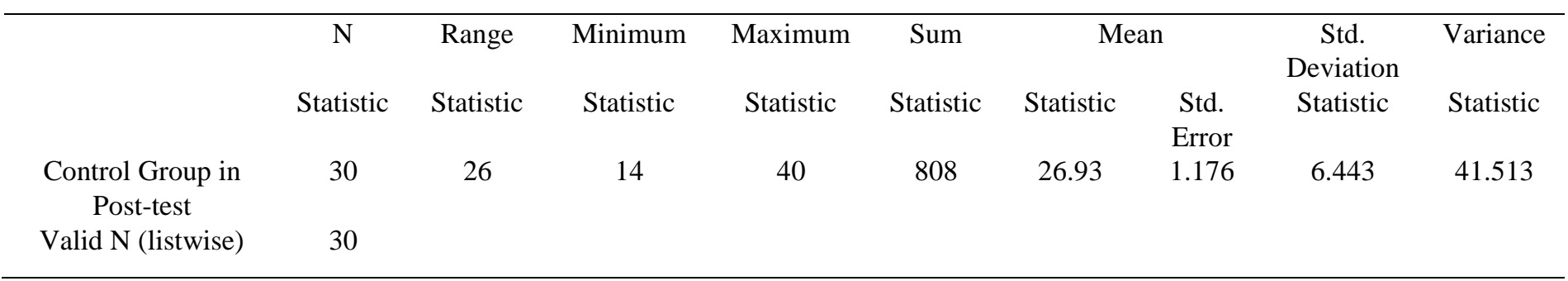

The descriptive statistics of the scores and their frequency of the participants in control group after treatment are depicted in the following table.

Table 5. Descriptive Statistics of Experimental Group in Post-test

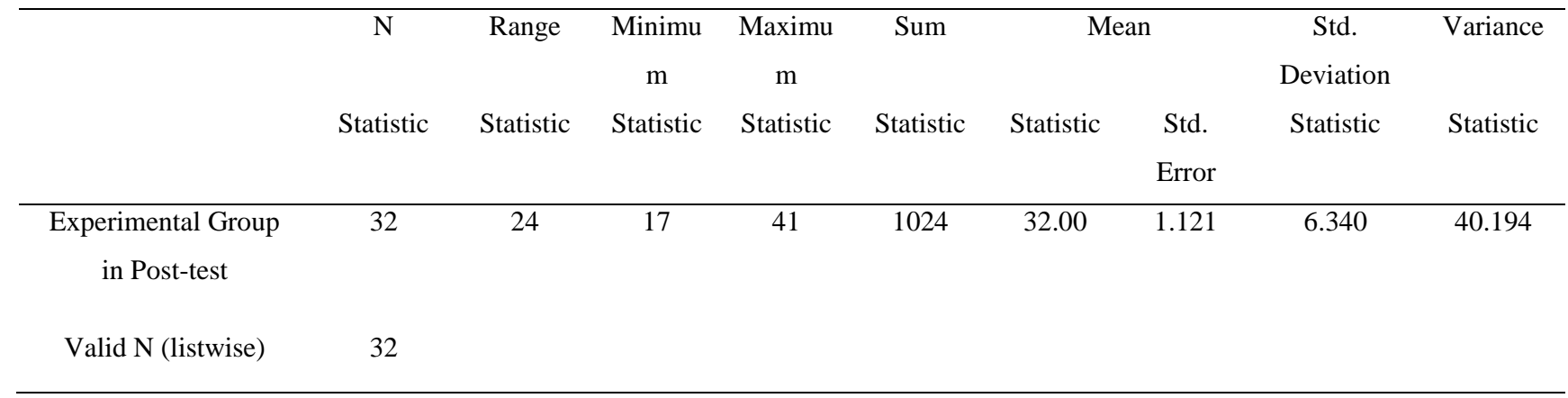

Table 6 provides enough criteria for the rejection of the null hypothesis of this study, because P-value which is .003 is less than .05. So it shows a significant difference. Furthermore the t-value observed which 3.131is is more than the $\mathrm{t}-$ value critical at the 0.05 level of significance (1.67). Therefore, we can safely claim that the experimental group outperformed the control group.

Table 6. Dependent Samples Test to compare the mean of two groups before treatment

\begin{tabular}{|c|c|c|c|c|c|c|c|c|c|c|}
\hline & & \multicolumn{2}{|c|}{$\begin{array}{l}\text { Levene's Test } \\
\text { for Equality of } \\
\text { Variances }\end{array}$} & \multicolumn{7}{|c|}{ t-test for Equality of Means } \\
\hline & & \multirow[t]{2}{*}{$\mathrm{F}$} & \multirow[t]{2}{*}{ Sig. } & \multirow[t]{2}{*}{$\mathrm{T}$} & \multirow[t]{2}{*}{ df } & \multirow[t]{2}{*}{$\begin{array}{l}\text { Sig. (2- } \\
\text { tailed) }\end{array}$} & \multirow[t]{2}{*}{$\begin{array}{l}\text { Mean } \\
\text { Difference }\end{array}$} & \multirow[t]{2}{*}{$\begin{array}{l}\text { Std. Error } \\
\text { Difference }\end{array}$} & \multicolumn{2}{|c|}{$\begin{array}{l}95 \% \text { Confidence } \\
\text { Interval of the } \\
\text { Difference }\end{array}$} \\
\hline & & & & & & & & & Lower & Upper \\
\hline \multirow[t]{2}{*}{ Scoree } & $\begin{array}{l}\text { Equal variances } \\
\text { assumed }\end{array}$ & .005 & $\begin{array}{l}.94 \\
6\end{array}$ & -3.137 & 60 & .003 & -5.078 & 1.625 & -8.348 & -1.848 \\
\hline & $\begin{array}{l}\text { Equal variances } \\
\text { not assumed }\end{array}$ & & & -3.136 & 59.613 & .003 & -5.078 & 1.626 & -8.350 & -1.846 \\
\hline
\end{tabular}


The similarity between Post-test mean score in Control Group and Post-test mean score in Experimental Group is depicted in Figure 2.

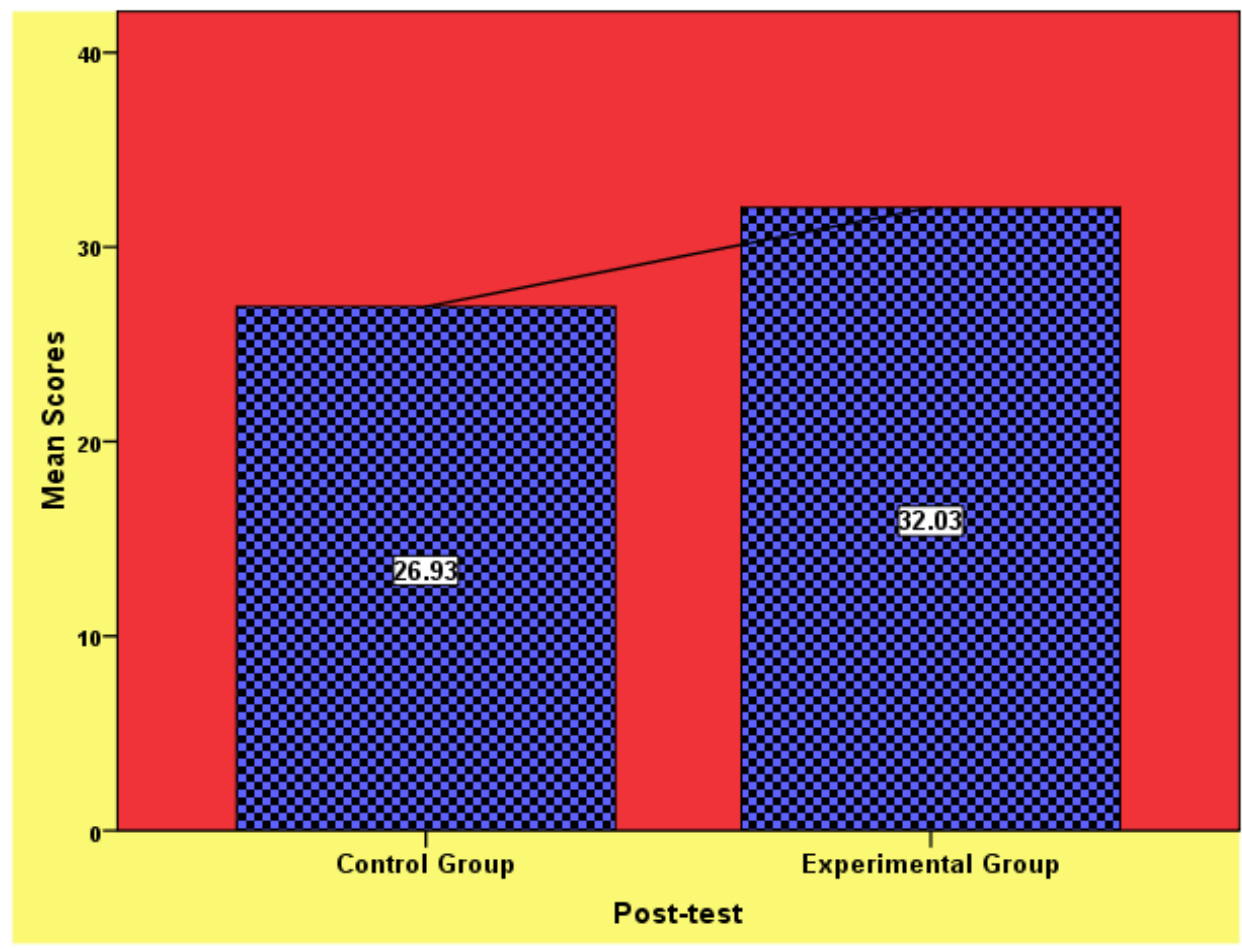

Figure 2. Bar Graph for the comparison of two groups after treatment

\section{Conclusion}

In this study the researcher tried to investigate whether tasks have any effect on adjective learning or not. To achieve this purpose, the following research question was set forth by the researcher:

Q: Does using authentic tasks have any significant effect on adjective learning?

To find the crucial answer to this research question, the following null hypothesis was stated:

$\mathrm{H}^{\mathrm{o}}$ : There is no significant difference between the intermediate EFL learners who learn adjective through using authentic task and that of those who do not.

Then, a proficiency test was administered to minimize the individual difference among learners and to make certain the homogeneity of them. Then, before starting the treatment, a vocabulary test was given to the learners to see if the knowledge of vocabulary items already exists among participants or not. After the test, the known words even by one learner were omitted from the whole study. Subsequently, each group received an especial kind of treatment for 12 sessions. At the end, a multiple choice vocabulary post-test similar to the pre-test was administered.

To analyze the findings of the study, SPSS (Statistical Package for social science) was utilized and the obtained results indicated that using authentic tasks contributed to the enhancement of adjective learning. Hence, it allowed the researcher to reject the null hypothesis.

The results obtained from the present study will contribute to a better understanding of adjective learning through authentic tasks. They would put emphasis on the advantages of task application which can foster learners' encouragement. To boost vocabulary acquisition and adjective learning as well, teacher and material developers could provide authentic materials as they are encouraging and leading to a better learning.

To sum up, we can safely claim that teaching and learning adjectives through using an authentic task is more useful and had noticeable effect on learners, than using a traditional vocabulary list.

\section{References}

Blachowicz, C. L., \& Fisher, P. (2004). Vocabulary lessons. Educational Leadership March, 66-69.

Blackburn, J. (2003). Authentic Learning and Teacher Evaluation. Retrieved January 6, 2004.)

Carlson, A. (2004). Authentic learning: What does it really mean? Retrieved January 25, 2005http://pandora.cii.edu/showcase2001/authentic_learning.htm

Grains, R., \& Redman, S. (1995). True to life: Teachers' book Edinburgh: Cambridge University Press.

Kojic-Sabo, I., \& Lightbown, P. M. (1999). Students' approaches to vocabulary learning and their relationship to success. The Modern Language Journal 83, 176-192. 
Lynch, J. (1997). Nudge, nudge: Teacher interventions in task-based learner talk. ELT Journal,51(4), 317-315. in Newton (2001).

McCarty, M., \& O’Dell, F. (1994). English vocabulary in use. Cambridge: Cambridge University Press.

Moras, D. (2001). Teaching vocabulary to advanced students: A lexical approach, Retrieved October 15, 2005.

Mueller, J. (2003). Authentic assessment toolbox. Retrieved October 8, 2005, from http://jonathan.mueller.faculty.nuctrl.edu

Nunan, D. (1989). Designing tasks for the communicative classroom. Cambridge: Cambridge University Press.

Nunan, d. (1991). Communicative tasks and the language curriculum. TESOL Quarterly, 25(2), 279-95.

Nunan, D. (1999). The conceptual basis of second language teaching and learning. Second language teaching and learning (pp. 6-37). Boston: Heinle and Heinle publishers.

Richards, J. C., \& Rodgers, T. S. (2001). Approaches and methods in language teaching. Cambridge: Cambridge University Press.)

Richards, J. C., Platt, J., \& Platt, H. (1992).Dictionary of language teaching and applied linguistics. (2 ${ }^{\text {sc }}$ ed.).

Rivers, W. M. (1981). And what else. Teaching foreign-language skills, second edition (pp. 464- 470). Chicago: The University of Chicago Press.

Skehan, P. (2002). A non-marginal role for tasks. ELT Journal, 56(3), 289-295.

Thornbury, S. (2004). The lexical approach: A journey without maps. English Teaching Professional, 7(4), 7-13. 